\title{
Acute SSRI Administration Affects the Processing of Social Cues in Healthy Volunteers
}

\author{
CJ Harmer*,', Z Bhagwagar', DI Perrett², BA Völlm', PJ Cowen' and GM Goodwin' \\ 'University Department of Psychiatry, Warneford Hospital, Oxford, UK; ${ }^{2}$ School of Psychology, University of St Andrews, Scotland
}

\begin{abstract}
Enhancement of serotonin neurotransmission plays an important role in the antidepressant response to agents presently available to treat depression. This response forms the major evidence for the role of serotonin in affective and social behaviour in humans. The present study investigated the effects of acute administration of the selective serotonin reuptake inhibitor (SSRI), citalopram (I 0 mg, i.v.) upon a measure of emotional processing in healthy female volunteers. Subjects completed a facial expression recognition task following infusion of citalopram or saline (between-subjects design, double-blind). Facial expressions associated with five basic emotions-happiness, sadness, fearfulness, anger and disgust - were displayed. Each face had been 'morphed' between neutral (0\%) and each emotional standard (100\%) in 10\% steps, leading to a range of emotional intensities. Mood and subjective experience were also monitored throughout the testing session. Volunteers receiving citalopram detected a higher number of facial expressions of fear and happiness, with reduced response times, relative to those given the placebo. By contrast, changes in the recognition of other basic emotions were not observed following citalopram. Notable differences in mood were also not apparent in these volunteers. These results suggest that acute administration of antidepressant drugs may affect neural processes involved in the processing of social information. This effect may represent an early acute effect of SSRIs on social and emotional processing that is relevant to their therapeutic actions. Neuropsychopharmacology (2003) 28, 148-152. doi:I 0. I 038/sj.npp. 1300004
\end{abstract}

Keywords: selective serotonin reuptake inhibitor; antidepressant; citalopram; facial expressions; emotion

\section{INTRODUCTION}

Selective serotonin reuptake inhibitors (SSRIs) such as fluoxetine and paroxetine are effective in a wide range of emotional disorders, including depression, panic disorder, obsessive compulsive disorder and social phobia (Fuller, 1995; Kent et al, 1998). The ability of SSRIs to potentiate brain serotonin neurotransmission has been well characterised in numerous studies of human and other animal species (Beasley et al, 1992; Blier and De-Montigny, 1994), but there is little understanding of the neuropsychological mechanisms by which increases in brain serotonin function could be translated into therapeutic efficacy in clinical disorders characterised by emotional and social dysfunction.

Investigations with animals and humans suggest that serotonin is involved in social behaviour. In nonhuman primates, administration of SSRIs or the serotonin precursor, 1-tryptophan, facilitated the acquisition of social dominance, reduced aggression and increased the frequency of affiliative behaviours such as grooming (Raleigh et al, 1991). Similarly, in healthy human volunteers, repeated (4 week) administration of the SSRI, paroxetine increased

\footnotetext{
* Correspondence: Dr CJ Harmar, University Department of Psychiatry, Warneford Hospital, Oxford OX3 7JX, UK. Fax: +44 I865 25I076, Email: catherine.harmer@psych.ox.ac.uk
}

Received 6 November 200 I; revised 6 June 2002; accepted I July 2002 cooperation in a problem-solving task and reduced ratings of negative affect (Knutson et al, 1998). Administration of l-tryptophan has also been reported to increase assertive behaviours over a 12-day period in healthy volunteers (Moskowitz et al, 2001). Taken together, these results suggest that serotonergic mechanisms may be involved in social affiliation and dominance.

Facial expressions are crucially important in social cognition and communication, providing information concerning the internal emotional states and intentions of other people. Ekman (1992) has described a number of basic emotions accompanied by specific facial expressions that are universally recognised throughout the human societies tested so far. Recognition of these different expressions appears to be processed by neural substrates associated with the behavioural functions of these emotions. For example, the processing of fear from facial expressions is modulated by the amygdala, which plays a wider role in both conditioned and unconditioned fear (reviewed by Davis and Whalen, 2001). Patients with bilateral lesions of this structure show a selective impairment in the recognition of fear (Adolphs et al, 1994, 1999; Broks et al, 1998), although similar impairments have been reported following neurologic damage unrestricted to the amygdala (Rapcsak et al, 2000). Neuroimaging studies in healthy volunteers reported activation of the amydgala during the processing of fear (Morris et al, 1996; Phillips et al, 1998), which correlated 
with the intensity of emotion presented (Morris et al, 1996). By contrast, the anterior insula and caudate have been implicated in the processing of disgust. Patients with Huntington's disease show impaired recognition of disgusted facial expressions even before the appearance of clinical symptoms, when the caudate nucleus is preferentially affected (Gray et al, 1997). Insula and basal ganglia damage has also been associated with an impairment in the recognition of facial and vocal signs of disgust (Calder et al, 2000) and, consistent with this, the anterior insula shows increased activity when viewing disgusted facial expressions (Phillips et al, 1997, 1998).

We reasoned that differentiated neuronal representations of the basic emotions might be accompanied by relatively selective modulation by different neurotransmitters. Some recent studies have described selective effects of pharmacological challenges on recognition of specific facial expressions. For example, administration of the benzodiazapine diazepam specifically decreased the recognition of anger (Blair and Curran, 1999) and fear (Zangara et al, 2002), while beta-adrenergic blockade impaired the processing of sad facial expressions (Harmer et al, 2001). Peturbutation of a particular neurochemical system may, therefore, lead to selective changes in the processing of one or a subset of emotional expressions. This might impose consequent biases in perception and interpersonal functioning. Such effects would be of relevance to the neurobiology of mood and anxiety disorders and also the mode of action of the pharmacological agents used to treat them.

Assessment of serotonergic function in the recognition of facial expression was of particular interest given its central role in the aetiology and treatment of mood disorder. There exists little understanding of the role of this neurotransmitter in normal emotional and social processing. Further, investigation of the early effects of antidepressant drugs on emotional processing may be pertinent to their clinical effects on mood, anxiety and social performance seen after longer term treatment. The present study, therefore, assessed the acute effects of an SSRI (citalopram) relative to placebo upon recognition of facial expression in healthy volunteers. It was predicted that citalopram administration would reduce the perception of negative facial expressions of emotion, while facilitating identification of positive facial expressions.

\section{METHODS}

\section{Subjects}

In all, 24 healthy female volunteers between the ages of 21 and 59 years took part in this study. Participants were screened to exclude those with a current or previous history of psychiatric disorder (assessed using a semistructured interview for DSM IV) or significant physical illness. All gave their written consent to participate in the study, which was approved by the local ethical committee. Volunteers were randomly allocated to receive citalopram (10 mg, i.v.) or placebo. These two groups were matched in terms of age (mean age: $40.1 \pm 3.6$ and $37.3 \pm 3.7$ years, respectively) and years of education (mean: $13.4 \pm 0.7 ; 14$. $6 \pm 0.7)$.

\section{Facial Expression Recognition}

The facial expression recognition task featured five basic emotions - happiness, sadness, fear, anger and disgusttaken from the Ekman and Friesen (1976) Pictures of Affect Series. These had been morphed between each prototype and neutral using techniques described by Young et al (1997). Briefly, this procedure involved taking a variable percentage of the shape and texture differences between the two standard images $0 \%$ (neutral) and $100 \%$ (full emotion) in $10 \%$ steps. Four examples of each emotion at each intensity were given. Each face was also given in a neutral expression, giving a total of 210 stimuli presentations. Each face was presented for $500 \mathrm{~ms}$ and was immediately replaced by a blank screen. Subjects made their response by pressing a labelled key on a response box. The task was broken down into three parts, with an untimed rest period between each to prevent fatigue. Subjects were asked to respond as quickly and as accurately as possible.

\section{Subjective State}

Subjective state was recorded using visual analogue scales for the following variables: happiness, sadness, fear, disgust, anger, alertness and anxiety. The Befindlichkeits Scale (BFS: von Zerrsen et al, 1974) was also given to provide an additional measure of mood.

\section{Procedure}

Subjects attended the laboratory at midday, having fasted from breakfast, and an intravenous cannula was inserted. After a 30-min rest period, subjects received infusion of either citalopram $10 \mathrm{mg}$ or placebo over $30 \mathrm{~min}$ in a doubleblind between-groups design. Subjects completed a facial recognition task $30 \mathrm{~min}$ after the end of the infusion. Previous work indicates that plasma prolactin levels, which are indicative of central serotonin, are elevated from the end of the citalopram infusion for at least $2 \mathrm{~h}$ (Attenburrow et al, 2001). Subjective state was assessed at baseline and prior to the psychological testing.

\section{STATISTICS}

Interrelationships between subjective ratings of mood and energy were explored using principal component analysis on the scores of all volunteers at baseline. Summed ratings were analysed using two-way analysis of variance with group (citalopram or placebo) and time of rating (baseline or postinfusion) as factors.

Speed and accuracy from the facial expression recognition task were also analysed using two-way analysis of variance with group and facial expression (anger, disgust, fear, happiness, and sadness) as factors. Significant interactions were analysed further using simple main effect analyses. Analyses of covariance were used to control for subjective mood on facial expression recognition.

\section{RESULTS}

\section{Subjective State}

Exploratory factor analysis on ratings of subjective state yielded a three-factor solution, which accounted for $80 \%$ of 
Table I Subjective State Ratings before and after Infusion of Citalopram or Placebo

\begin{tabular}{|c|c|c|c|c|c|}
\hline & \multicolumn{2}{|c|}{ Baseline } & \multicolumn{2}{|c|}{ Postinfusion } & \multirow[b]{2}{*}{ Significance } \\
\hline & Placebo & Citalopram & Placebo & Citalopram & \\
\hline Negative mood & $\begin{array}{l}5.5 \\
(2.6)\end{array}$ & $\begin{array}{l}7.5 \\
(4.3)\end{array}$ & $\begin{array}{l}7.8 \\
(3.4)\end{array}$ & $\begin{array}{l}5.2 \\
(3.8)\end{array}$ & $F(1,22)=4.2, p=0.05$ \\
\hline Positive mood & $\begin{array}{l}139.2 \\
(14.1)\end{array}$ & $\begin{array}{l}\mid 48.0 \\
(14.5)\end{array}$ & $\begin{array}{l}150.3 \\
(13.8)\end{array}$ & $\begin{array}{l}136.3 \\
(14.3)\end{array}$ & $F(1,22)=2.5, p=0.1$ \\
\hline Anxiety & $\begin{array}{l}20.5 \\
(7.2)\end{array}$ & $\begin{array}{l}16.7 \\
(3.4)\end{array}$ & $\begin{array}{l}10.6 \\
(3.4)\end{array}$ & $\begin{array}{l}14.1 \\
(3.6)\end{array}$ & $F(1,22)=1.2, p=0.3$ \\
\hline
\end{tabular}

A principal analysis of the subjective state ratings at baseline revealed a three-factor solution: negative mood (anger, disgust and fear); positive mood (happy, alertness and inverted sadness); and anxiety (anxiety and BFS ratings).

Statistical values represent the interaction term between group and time of rating.

the observed variance. These factors (from highest to lowest eigenvalue) were negative affect, positive affect and anxiety (see Table 1). There was no effect of citalopram on positive mood or anxiety (see Table 1) although there was a marginal interaction between time of rating and group in terms of negative affect $(\mathrm{F}(1,22)=4.2, p=0.05)$. However, pairwise comparisons at baseline $(t(1,22)=0.4, p=0.7)$ and after infusion $(t(1,22)=-0.5, p=0.6)$ failed to reveal significant differences between the two groups in negative mood ratings.

\section{Facial Expression Recognition}

Compared to saline, citalopram-treated subjects were selectively more accurate at identifying facial expressions of fear and happiness in the absence of changes in recognition of the other facial expressions (see Figure 1: group $\times$ emotion interaction $\mathrm{F}(4,88)=3.0, p=0.03)$. Inclusion of the three subjective state ratings (post-infusion) as covariates did not abolish the significant differences between the two groups in terms of fear $(F(1,19)=4.7$, $p<0.05)$ or happiness $(\mathrm{F}(1,19)=5.1, p<0.05)$ recognition. Hence, the enhanced recognition of these emotions appears unrelated to subjective state.

The number of emotions misclassified as fear and happiness did not differ significantly between the two groups, suggesting that increased recognition of these emotions was not the result of a nondiscriminatory change in labeling faces as these emotions (group $\times$ emotion: $\mathrm{F}(5,110)=1.6, p=0.2$; happiness $\mathrm{F}(1,22)=1.5, p=0.2$; fear $\mathrm{F}(1,22)=1.6, p=0.2)$.

Because of the possibility that these differences may represent a change in speed-accuracy trade-off, the reaction time of correct identifications was also computed. The speed to identify facial expressions of fear and happiness was selectively faster in subjects treated with citalopram relative to placebo (Figure 1: happiness $\mathrm{F}(1,22)=7.1$, $p=0.01$; fear: $\mathrm{F}(1,22)=4.5, p<0.05$; all other emotions NS), suggesting that this SSRI improved the overall efficiency with which these emotions were recognised. These group differences were not affected by inclusion of subjective ratings as covariates (fear: $\mathrm{F}(1,19)=5.8, p=0.03$; happiness: $\mathrm{F}(1,19)=7.2, p=0.02)$.

To explore the effect of citalopram in more detail, accuracy of fear and happiness recognition was analysed over the different morphed intensity levels presented in a random order during this task (Figure 2). In both cases, citalopram shifted the recognition function to the left: lower levels of emotional intensity were recognised more consistently in the citalopram-treated subjects, while the higher levels were, as expected, at ceiling levels in both groups (group $\times$ intensity: happiness $\mathrm{F}(9,198)=2.8, p<0.01$; fear $\mathrm{F}(9,198)=3.6, p<0.001)$. Examination of the other facial expressions over different intensity levels failed to identify any differences between citalopram- and placebo-treated subjects in this more detailed analysis, confirming a specific action on happiness and fear (main effect of group and group $\times$ intensity interactions respectively: sadness $\quad \mathrm{F}(1,22)=0.01, \quad p=0.9 ; \quad \mathrm{F}(9,198)=1.4, \quad p=0.2$; anger $\mathrm{F}(1,22)=1.4, p=0.3 ; \mathrm{F}(9,198)=0.5, p=0.9$; disgust $\mathrm{F}(1,22)=0.2, p=0.7 ; \mathrm{F}(9,198)=0.8, p=0.6)$.

\section{DISCUSSION}

These data indicate that acute potentiation of central serotonin neurotransmission facilitated the recognition of facial expressions of happiness and fear. This effect was highly selective: subjects were both faster and better at detecting facial expressions of these emotions in the absence of changes in processing other emotions. These data are in line with the hypothesis that the recognition of different emotional states involves dissociable neurocognitive systems. In particular, serotonin may play a specific role in the processes involved in the recognition of happiness and fear.

The present differences in the recognition of emotional states following citalopram occurred in the absence of significant changes in subjective mood and were not affected by inclusion of mood ratings as covariates. These results suggest that shifts in the processing of emotional information can occur independently, or at a lower threshold, than overt differences in mood. As such, this model may be useful in the detection of early effects of antidepressants preceding the development of conscious mood changes.

The present facilitation of happiness recognition is consistent with evidence suggesting a role for serotonin in social behaviour. Repeated SSRI administration has been reported to increase affiliative behaviour in primates (Raleigh et al, 1991) and humans (Knutson et al, 1998). However, while the previous studies have measured 

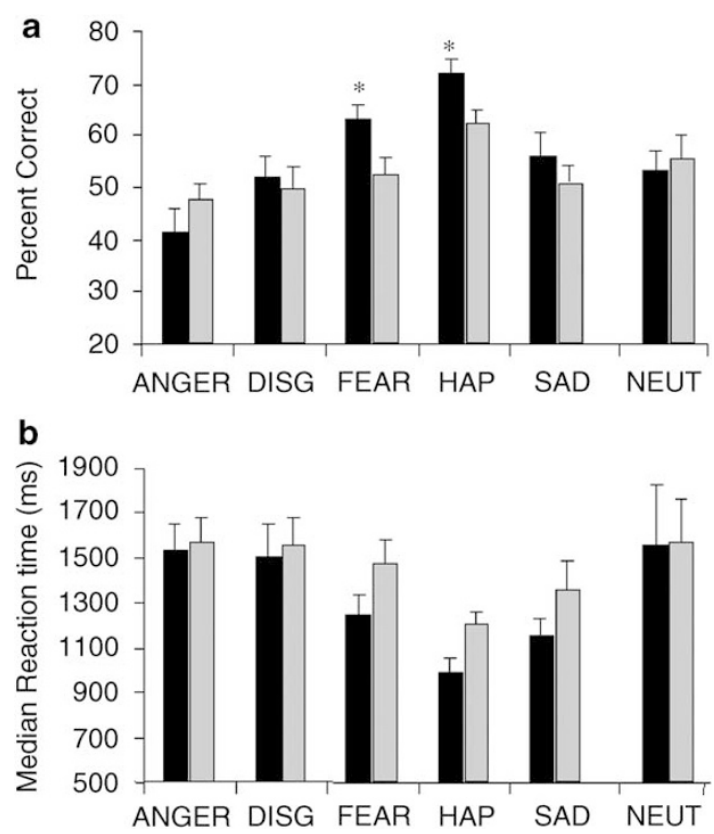

Figure I Performance in the facial expression recognition task following citalopram (dark bars) or placebo (light bars). Top graph: Percentage of correct responses for each emotion. Asterisks illustrate the statistical significance of simple main effect analyses: $* p<0.05$. Lower graph: Reaction time of correct responses for each emotion. Simple main effect analyses revealed a significant facilitation in the speed with which fear $(p<0.05)$ and happiness $(p<0.02)$ were detected in the absence of changes in speed to recognise other basic emotions.

affiliative behaviour, the present results suggest that enhanced perception of affiliative signals also occurs with SSRI administration. Indeed, an enhanced perception of happiness would be predicted to facilitate approach behaviour and social interaction. These changes may also be relevant to aspects of the action of SSRIs in patients with depression, who have been reported to show negative biases in the perception of social stimuli (eg Bouhuys et al, 1999).

Citalopram administration also facilitated the recognition of fear from facial expression, which was contrary to our hypothesis of reduced identification of negative emotions following SSRI administration. This result may be related to the fact that citalopram was given acutely in the present study. Indeed, we have recently found decreased recognition of fearful, disgusted and surprised facial expressions following a 7-day oral treatment with this SSRI (Harmer et $a l, 2002)$. Opposite effects of acute and repeated administration of antidepressants have also been reported in preclinical models of anxiety (Griebel et al, 1994) and, clinically, symptoms of agitation or panic can be exacerbated initially with SSRI treatment (Kent et al, 1998). Hence, the present facilitation of fear recognition may reflect enhanced processing of threatening cues in the environment following SSRI challenge.

A role for serotonin in the processing of fear-related signals has been identified both in animal and human models. In rats, serotonin levels in the amygdala increased during inescapable stress and conditioned fear (Amat $e t a l$, 1998; Kawahara et al, 1993; Inoue et al, 1993). In humans, acute administration of serotonin-receptor blockers has been reported to decrease the development of conditioned
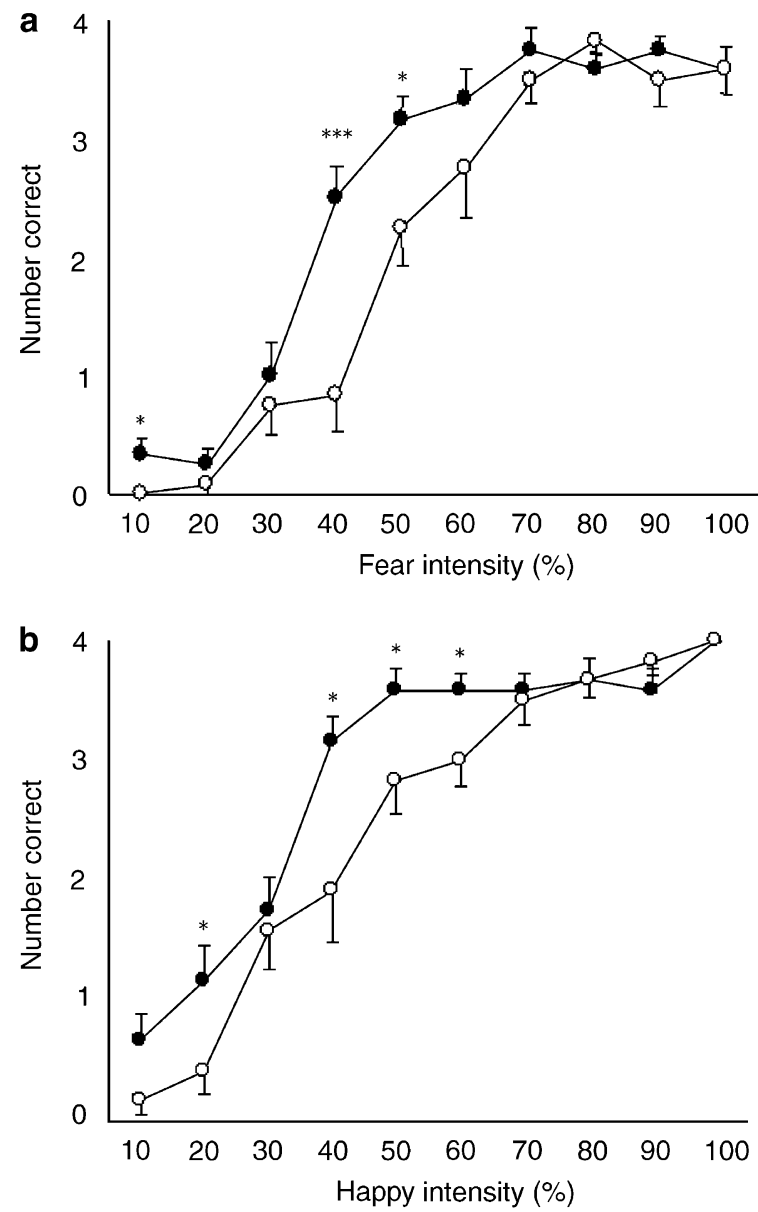

Figure 2 Recognition of fear and happiness over the different intensity levels of facial expression used in this task. - -, following citalopram; -O-, following placebo. Top graph: fear recognition. Lower graph: happiness recognition. Asterisks illustrate the statistical significance of simple main effect analyses: $* p<0.05$, $* * * * 00.00$ I.

responses to an aversive loud noise as measured by subjective report and skin conductance responses (Hensman et al, 1991; Silva et al, 2001). The role of the amygdala in conditioned fear is well established (Maren, 2001); and has also been implicated in the processing of fearful facial expressions (Adolphs et al, 1994, 1999; Morris et al, 1996). It is therefore possible that serotonergic input to the amygdala may modulate the detection of fearful expressions in addition to its role in conditioned anxiety in human and animal models (see Graeff et al, 1996). It is tempting to speculate that the increased and decreased fear perception found after acute compared to repeated administration of SSRIs relates to opposing effects on neural substrates involved in fear processing such as the amygdala, and that these changes may be relevant to the therapeutic actions of SSRI in depression and anxiety, both of which have been associated with amygdala hyperarousal (Drevets et al, 1992; Sheline et al, 2001; Rauch et al, 2000).

In summary, acute administration of the SSRI citalopram facilitated the recognition of fear and happiness from facial expressions. These effects may relate to effects of serotonin on affiliative behaviour and the processing of fear-related cues. Further research is needed to assess whether these effects interact with changes in the processing of facial 
expressions produced by mood and anxiety disorders. Also, future studies should assess whether similar effects are apparent in male as well as female volunteers. If confirmed, these interpretations may begin to bridge the gap between narrowly defined pharmacological theories of drug action and an alternative, more integrated understanding based on the function of brain networks subserving emotional processing.

\section{REFERENCES}

Adolphs R, Tranel D, Damasio H, Damasio A (1994). Impaired recognition of emotion in facial expressions following bilateral damage to the human amygdala [see comments]. Nature 372: 669-672.

Adolphs R, Tranel D, Hamann S, Young AW, Calder AJ, Phelps EA et al (1999). Recognition of facial emotion in nine individuals with bilateral amygdala damage. Neuropsychologia 37: 1111-1117.

Amat J, Matus-Amat P, Watkins LR, Maier SF (1998). Escapable and inescapable stress differentially alter extracellular levels of 5HT in the basolateral amygdala of the rat. Brain Res 812: 113-120.

Attenburrow MJ, Mitter PR, Whale R, Terao T, Cowen PJ (2001). Low dose citalopram as a 5-HT neuroendocrine probe. Psychopharmacology 155: 323-326.

Beasley CM, Masica DN, Potvin JH (1992). Fluoxetine: a review of receptor and functional effects and their clinical implications. Psychopharmacology 107: 1-10.

Blair RJ, Curran HV (1999). Selective impairment in the recognition of anger induced by diazepam. Psychopharmacology (Berl) 147: 335-338.

Blier P, De-Montigny C (1994). Current advances and trends in the treatment of depression. Trends Pharmcol Sci 15: 220-226.

Bouhuys AL, Geerts E, Gordijn MC (1999). Depressed patients' perceptions of facial emotions in depressed and remitted states are associated with relapse: a longitudinal study. J Nerv Ment Dis 187: 595-602.

Broks P, Young AW, Maratos EJ, Coffey PJ, Calder AJ, Isaac CL et al (1998). Face processing impairments after encephalitis: amygdala damage and recognition of fear. Neuropsychologia 36: 59-70.

Calder AJ, Keane J, Manes F, Antoun N, Young AW (2000). Impaired recognition and experience of disgust following brain injury. Nat Neurosci 3: 1077-1078.

Davis M, Whalen PJ (2001). The amygdala: vigilance and emotion. Mol Psychiatry 6: 13-34.

Drevets WC, Videen TO, Price JL, Preskorn SH, Carmichael ST, Raichle ME (1992). A functional anatomical study of unipolar depression. J Neurosci 12: 3628-3641.

Ekman P (1992). An argument for basic emotions. Cognition Emotion 6: 169-200.

Ekman P, Friesen WV (1976). Pictures of Facial Affect Consulting Psychology. Palo Alto, CA.

Fuller RW (1995). Serotonin uptake inhibitors: uses in clinical therapy and in laboratory research. Prog Drug Res 45: 167-204.

Griebel G, Moreau JL, Jenck F, Misslin R, Martin JR (1994). Acute and chronic treatment with 5-HT reuptake inhibitors differentially modulate emotional responses in anxiety models in rodents. Psychopharmacology 113: 463-470.

Graeff FG, Guimaraes FS, De Andrade TG, Deakin JF (1996). Role of 5-HT in stress, anxiety, and depression. Pharmacol Biochem Behav 54: 129-141.

Gray JM, Young AW, Barker WA, Curtis A, Gibson D (1997). Impaired recognition of disgust in Huntington's disease gene carriers. Brain 120: 2029-2038.
Harmer CJ, Perrett DI, Cowen PJ, Goodwin GM (2001). Administration of the beta-adrenoceptor blocker, propranolol, impairs the processing of facial expressions of sadness. Psychopharmacology (Berl) 154: 383-389.

Harmer CJ, Shelley NC, Cowen PJ, Goodwin GM (2002). Repeated administration of citalopram or reboxetine reduces the perception of negative emotions from facial expression. $J$ of Psychopharmacol. S16, A70.

Hensman R, Guimaraes FS, Wang M, Deakin JF (1991). Effects of ritanserin on aversive classical conditioning in humans. Psychopharmacology (Berl) 104: 220-224.

Inoue T, Koyama T, Yamashita I (1993). Effect of conditioned fear stress on serotonin metabolism in the rat brain. Pharmacol Biochem Behav 44: 371-374.

Kawahara H, Yoshida M, Yokoo H, Nishi M, Tanaka M (1993). Psychological stress increases serotonin release in the amygdala and prefrontal cortex assessed by in vivo microdialysis. Neurosci Lett 162: 81-84.

Kent JM, Coplan JD, Gorman JM (1998). Clinical utility of the selective serotonin reuptake inhibitors in the spectrum of anxiety. Biol Psychiatry 44: 812-824.

Knutson B, Wolkowitz OM, Cole SW, Chan T, Moore EA, Johnson RC et al (1998). Selective alteration of personality and social behavior by serotonergic intervention. Am J Psychiatry 155: 373-379.

Maren S (2001). Neurobiology of Pavlovian fear conditioning. Annu Rev Neurosci 24: 897-931.

Morris JS, Frith CD, Perrett DI, Rowland D, Young AW et al (1996). A differential neural response in the human amygdala to fearful and happy facial expressions. Nature 383: 812-815.

Moskowitz DS, Pinard G, Zuroff DC, Annable L, Young SN (2001). The effect of tryptophan on social interaction in everyday life: a placebo-controlled study. Neuropsychopharmacology 25: 277-289.

Phillips ML, Young AW, Scott SK, Calder AJ, Andrew C, Giampietro V et al (1998). Neural responses to facial and vocal expressions of fear and disgust. Proc R Soc Lond B Biol Sci 265: 1809-1817.

Phillips ML, Young AW, Senior C, Brammer M, Andrew C, Calder AJ et al (1997). A specific neural substrate for perceiving facial expressions of disgust. Nature 389: 495-498.

Raleigh MJ, McGuire MT, Brammer GL, Pollack DB, Yuwiler A (1991). Serotonergic mechanisms promote dominance acquisition in adult male vervet monkeys. Brain Res 559: 181-90.

Rapcsak SZ, Galper SR, Comer JF, Reminger SL, Nielsen L, Kaszniak AW et al (2000). Fear recognition deficits after focal brain damage: a cautionary note. Neurology 54: 575-581.

Rauch SL, Whalen PJ, Shin LM, McInerney SC, Macklin ML, Lasko NB (2000). Exaggerated amygdala response to masked facial stimuli in posttraumatic stress disorder: a functional MRI study. Biol Psychiatry 47: 769-776.

Silva M, Hetem LA, Guimaraes FS, Graeff FG (2001). Opposite effects of nefazodone in two human models of anxiety. Psychopharmacology (Berl) 156: 454-460.

Sheline YI, Barch DM, Donnelly JM, Ollinger JM, Snyder AZ, Mintun MA (2001). Increased amygdala response to masked emotional faces in depressed subjects resolves with antidepressant treatment: an fMRI study. Biol Psychiatry 50: 651-658.

von Zerrsen D, Strian F, Schwarz D (1974). Evaluation of depressive states, especially in longitudinal studies. In: Pichit $\mathrm{P}$ (ed). Psychological Measurements in Psychopharmacology. Basel, Switzerland: Karger, pp 189-202.

Young AW, Rowland D, Calder AJ, Etcoff NL, Seth A, Perrett DI (1997). Facial expression megamix: tests of dimensional and category accounts of emotion recognition. Cognition 63: 271-313.

Zangara A, Blair RJ, Curran HV (2002). A comparison of the effects of a beta-adrenergic blocker and a benzodiazepine upon the recognition of human facial expressions. Psychopharm 163: 36-41. 